\title{
Fuat Sezgin ve Bilim Tarihi Algısı
}

\section{Fuat Sezgin and the Perception of History of Science}

\author{
Prof. Dr. Abamüslim AKDEMİ (iD) 1
}

\begin{abstract}
$\ddot{\mathbf{O} z}$
2019 Prof. Dr. Fuat Sezgin Y1lı" kapsamında düzenlenen etkinliklere katkı sağlamak amacıyla yapılan bu çalışmada hem bilim tarihinin önemine hem de Fuat Sezgin üzerinden İslam dünyasının bilim tarihindeki yerinin nasıl algılandığını anlamayı amaçlamıştır. Çünkü bugün bilime bakış açımız ya tamamen batı kaynaklı ya da geçmişe nostaljik geçişler yaparak muhteşem mazinin yeniden doğuşunun peşine düşme şeklindedir. Bu iki durumda da taklidin ve mazinin yeniden arkaik doğuşunun yansımasından başka bir şey değildir. Bilim tarihi her ne kadar evrensel başarıların tarihi olsa da taşıdığı maddi kültür ögeleri ile de ortaya çıktığı toplumu medeniyetin merkezine yerleştirir. Her başarı onu doğuran medeniyetin adı ile anılır ve bulunduğu tarihsel dönemi temsil eder. Bu çerçevede bilim tarihi çalışmaları önemli olsa da bilim algısı daha önemlidir. "Fuat Sezgin Y1lı" kapsamında yapılan etkinlikler sadece toplantı, konferans vb. etkinliklerden ibaret kalırsa ancak günü kurtarır. Oysa asıl dikkat edilmesi gereken, Sezgin'in de birçok söyleşisinde ve özel sohbetlerinde vurguladığı gibi bilim tarihine katkı yapan medeniyetlerin mirasçısı olarak Müslümanların bugün de bilim dünyasında sadece kendileri için değil tüm insanlı̆̆ın yararına bir şeyler yapacak bir medeniyet projesi fikrine sahip olup olmadıklarıdır. Bu nedenle Fuat Sezgin üzerinden İslam dünyasının bilim tarihindeki yerinin nasıl algılandığını anlamayı hedeflemekteyiz. Bunu yaparken de, geleneği olmayan toplumların geleceği olmayacağı bilinciyle hareket ederek, geçmişten bugüne 1şık tutmanın bugünü doğru anlamada anahtar olacağı kanaatindeyiz.
\end{abstract}

Anahtar Kelimeler: Fuat Sezgin, bilim tarihi, bilim tarihi algısı, İslam dünyasında bilim

Makale Türü: Derleme

\begin{abstract}
In this study which was conducted to contribute to the activities organized within the scope of "2019 Prof. Dr. Fuat Sezgin Year", it is aimed to both the importance of the history of science and how the Islamic world perceived in the history of science through Fuat Sezgin because today our view to the science is either completely originating from West or a pursuit of the rebirth of magnificent past by making nostalgic transition to the past. In both cases, this is nothing but a reflection of an archaic rebirth of past and an imitation. Although the history of science is the history of universal achievements, it puts the society in which it emerges in the center of civilization thanks to the elements of its material culture. Every success is named after the civilization in which it arises from and represents the historical period it arised. In this context, the perception of science is more important than the study of the history of science. If activities organized in the scope of "Prof. Dr. Fuat Sezgin Year" are limited to activities like meetings and conferences, they just save the day. However, what needs to be taken into consideration, as Sezgin emphasized in many interviews and private conversations, is whether Muslims, as inheritor of the civilizations that contributed to the history of science, still have the idea of a civilization Project that is for the benefit of not only themselves but also whole humanity. Therefore, we aim to understand how the Islamic world perceived through Fuat Sezgin in the history of science. While doing this, by acting with the awareness that societies without tradition have no future, we think that shedding light from the past to the present is the key to understanding the present correctly.
\end{abstract}

Keywords: Fuat Sezgin, history of science, perception of the history of science, science in Islamic world Paper Type: Review

${ }^{1}$ Bursa Uludağ Üniversitesi, Eğitim Fakültesi, akdemir@uludag.edu.tr.

Atıf için (to cite): Akdemir, A. (2019). Fuat Sezgin ve Bilim Tarihi Algısı. Afyon Kocatepe Üniversitesi Sosyal Bilimler Dergisi, 21(Prof. Dr. Fuat Sezgin Özel Sayısı), 118-124. 
2019 Prof. Dr. Fuat Sezgin Yılı kapsamında düzenlenen etkinliklere katkı sağlamak amacıyla yapılan bu çalışmada hem bilim tarihinin önemine hem de Fuat Sezgin üzerinden İslam dünyasının bilim tarihindeki yerinin nasıl algılandığını anlamayı hedeflemekteyiz. Bunu yaparken de geleneği olmayanın geleceği olmayacağı bilinciyle hareket ederek, geçmişten bugüne 1şık tutmanın bugünü doğru anlamada anahtar olacağı kanaatindeyiz. Bu amaca hizmet etmeye yönelik çalışmaları ile dünya genelin de kabul gören ilk bilim tarihi doktorası yapan Prof. Dr. Aydın Sayılı (1913-1993) ve İslam dünyasının bilimsel başarılarını batıya tanıtan Prof. Dr. Fuat Sezgin'i (1924-2018) yeni nesillere tanıtmak elbette önemlidir. Ancak bunu yapmak çokta kolay değil, Sezgin'in de bir söyleşide söylediği “Batı Dünyası'nda bütün enstitülerde aşağı yukarı İslam Bilimleri ile uğraşan hepsinde var benim kitaplarım. Herkes bu kitapları kullanıyor, çalışıyorlar. Ama bizim Türkiye'de yok" (Sezgin, 2016: 19). Serzenişi haklı olarak bizdeki ilgisizliği göstermektedir. Sadece ilgide yetmez. Çünkü bugün bilime bakışımız ya tamamen batı kaynakl1 ya da geçmişe nostaljik geçişler yaparak muhteşem mazinin yeniden doğuşunun peşine düşme şeklindedir. Bu iki durumda taklidin ve mazinin yeniden arkaik doğuşunun yansımasından başka bir şey değildir. Bilim tarihi her ne kadar evrensel başarıların tarihi olsa da taşıdığı maddi kültür ögeleri ile de ortaya çıktığı toplumu medeniyetin merkezine yerleştirir. Her başarı onu doğuran medeniyetin adı ile anılır ve bulunduğu tarihsel dönemi temsil eder.

Bilim tarihi tarihin hiçbir döneminde hak ettiği ilgiyi görmedi. Bu durum birazda bilime duyulan ilgi ile doğru orantılıdır. Bilim J. Gribbin dediği gibi "insan aklının en büyük başarılarından biridir (belki de en büyüğü) ve ilerlemenin akıllı sıradan insanlarca aslında büyük oranda kendilerinden önce gelen nesillerin çalışmalarının izinde adım adım yürüyerek sağlanmış olması, bilim öyküsünü daha az değil, daha fazla ilginç kılmaktadır" (Gribbin, 2001: 14). Oysa A.Noyes ifadesi ile " Savaşları yücelttik ama bilim yüceltilmedi." Tarih kitaplarında, insanların cehaleti ve batıl itikatları kaldırıp atma yolunda gösterdikleri başarı değil, insanların başka insanları dize getirmedeki başarısından söz edilmektedir. İnsanların bilimdeki başarılarını kolay ve anlaşılır bir tarih kitabı yoktur. Ama insanların diğer insanlara hâkim olma mücadelesini anlatan birçok kitap bulunmaktadır. Maalesef savaşlar tarihin temel dayanağı olmaya devam ediyor. Bilim her erkek, kadın ve çocuğun hayatına daha fazla girmeli. Bu yolla insan aklının muhteşem macerasını anlayabiliriz. Çünkü bilim dünya üzerindeki bütün uygarlıklarında ortaya çıkmıştır. Bilimden korkma da cehaletten olduğu kadar, bilimin doğasını ve başlangıcını yanlış anlamaktan kaynaklanmaktadır (Ronan,2003: 2). Reinaud "Rastlant1, tekniklerin ve sanatların ilerlemesinde çok büyük rol oynamaz. İnsanlık bütün keşiflerinde istikrarlı bir şekilde ileriye doğru, birdenbire bir sıçrayışla değil, adım adım hareket eder. Her zaman aynı hızla ilerlemez, fakat hareket süreklidir. İnsan icat etmez, sonuçlar çıkarır." İlerleme tarihi aralıksız bir zincir oluşturur. Olgular tarihi bu zincirin parçalarını verir. Bilim tarihçileri kaybolan halkaları bularak birini diğerine ekleyerek parçayı tamamlamaktır (Sezgin, Önsöz, 2008: 13). Bu ise bilim tarihinin bütünlügünü sağlar.

Tarihsel dönemleri doğu ve batı arasında ilerleyen bir süreç olarak başlatan bilim tarihi genel çerçevesini Eski dönem, Orta çağ ve Modern zamanlar olarak çizer. Eski dönemlerin ilk halkası Mısır uygarlığıdır. Sonra "Bereketli Hilal" diye de adlandırılan Mezopotamya ile varlığını devam ettirmiştir. Furat ve Dicle nehrinin beslediği bu uygarlık Sümer, Akad ve Babil'le temsil edilmiştir. Doğu uygarlığının diğer bir tarihsel kökü de Hint ve Çin uygarlığıdır. Buradan batıya geçen bilimsel etkinlikler Grek dünyasında Antik Yunan'ın akılcı sistemleriyle tarihsel serüvenini sürdürmüştür (Topdemir ve Unat, 2013: 4). Bilim tarihinde Eski dönemlerle Modern zamanlar arasında yer alan Orta çağ yaklaşık bin yıllık bir zaman dilimini kapsar. Batılı bilim tarihçilerinin bir kısmı bu dönemi basite indirgeyerek karanlık çă̆ olarak adlandırmasının haklı nedenleri yoktur. Kaldı ki bu dönem sadece Hristiyan dünyadan ibaret değildir. 9-15 yy. arasında bilimde yaşadığı altın çağ ile büyük bir medeniyet oluşturan İslam dünyasının doğulu ve batılı birçok bilim insanı dikkat çektiği gibi İslam dünyasının döneme damgasını vurduğu aşikârdır.

Rönesans'1 yeniden doğuş ve eskiye dönüş olarak tanımlayan batı bilim tarihi algısında İslam dünyasını ve onun Rönesans üzerindeki etkisini yatsıma arzusu vardır. Bu ise bilim 
tarihinde özellikle de romantik dönemde tarihsel olgulara karşı adil olmayan periyotlaştırmadır. Gerçi önceki dönemlerde Raffaello'in Atina Okulu tablosunda Averroes adiyla İbn Rüşt'e yer vermesi, Herder, Goethe, Spengler ve Homboldt gibi düşünürlerin hümanist anlayışın da Müslümanlara bilim tarihinde layık olduğu takdiri yöneltmeleri dikkate değerdir. Bununla birlikte baba ve oğul Sédillat bilim dünyasının, İslâm kültür çevresinin ortaya koyduğu başarılara karş1 adil bir davranış için onlarca yıl mücadele vermelerini de görmemezlikten gelemeyiz. Ancak onların bu tavrı Fransız akademisi tarafından pek hoş karşılanmadı (Sezgin, Önsöz, 2008: 13). Fuat Sezgin de Arap-İslam Bilimleri Enstitüsü'ndeki çalışmalarında 800 y1l boyunca İslam dünyasında gerçekleşmiş olan başarılara yönelik küçümseyici algıları mümkün olduğunca değiştirmeyi amaçlamıştır. O yapılanları" biz bulduk" heyecanıyla değil bilakis bilimler tarihinin bütünlüğüne ve evrenselliğine hizmet etme olarak tanımlamıştır (2008: 15). Fuat Sezgin'in çalışmalarının sonuçlarından biri de hakkı kaybolan bir medeniyetin hakkını teslim etmeye dikkat çekmektir.

Dünyanın önemli İslam bilim tarihçilerinden biri olarak kabul edilen Fuat Sezgin, İstanbul Üniversitesi Şarkiyat Araştırmaları Enstitüsünde alanında en tanınmış uzmanlardan Alman şarkiyatçı Helmut Ritter'in öğrenci iken onun tavsiyesi üzerine İslam bilimlerine yöneldi. İslam kültür ve medeniyetinin daha iyi anlaşılması için pek çok çalışmaya imza attı. Özellikle 1965 yılında Frankfurt Üniversitesinde profesör olarak çalışmaya başlamasıyla birlikte Arapİslam kültürü çevresinde tabii bilimler tarihi alanında yoğunlaştı. Arap-İslam Edebiyatı tarihinde Edebiyattan, Coğrafyaya bütün konuları içine alan 13. ciltlik eserini tamamladı. Ayrıca 1982 yılında Goethe Üniversitesine bağlı olarak Arap-İslam Bilimleri Enstitüsü ve 1983'te kurduğu Müze ve kütüphane de binlerce eseri ve İslam dünyasının dönemine kazandırdığı teknik araçların birebir örneğini yaparak bilim insanlarının hizmetine sunmuştur. O çalışmalarında bütün insanlığın ortak bilim tarihinin en az sekiz yüzyıllık evresinin yapıcıları olma hakkını taşıyan İslam dünyasının modern dünya da karşılığını bulmasını amaçlar (Sezgin, 2016: 20). Ayrıca mevcut İslam topluluklarına mensup insanlara bilimlerin gerçeğini tanıtmak, benlik duygularını olumsuz etkileyen yanlış yargılardan kurtarmak ve ferdin yaratıcılığına olan inancı kazandırma çabasındadır.

Fuat Sezgin'in "İslam'da Bilim ve Teknik" adıyla Türkçe' ye de çevrilen beş ciltlik katalog eseri başta olmak üzere diğer bütün araştırmaları bilim tarihine yeni bir boyut kazandırmıştır. Ayrıca bu çalışmalar İslam kültür dünyasına unutmuş olduğu bilimsel geçmişini hatırlatmak ve yitirmiş olduğu belleği yeniden canlandırma yolunu da tarihi misyona sahiptir. İslam dünyasının bilim tarihinde Orta Çağın belirleyici halkası olması elbette sadece Fuat Sezgin'in belirlediği durum değildir. O bilimde altın çağını yaşayan bu medeniyetin hak ettiği yeri açığa çıkaran araştırmacılardan biridir. İslam dünyasının bilim tarihinin evrensel bir değeri olması bu dönemdeki bilime bakışı ve bilimsel başarılarının sonucudur. Sezgin'in çalışmalarında vurgulanan ve bilim tarihçiler tarafından da kabul edilen bu durum. Özellikle 9 ve 15 yüzyıllar arasındaki İslam dünyasının bilimsel faaliyetlerinin sonucudur. İslam dünyasını bilim tarihin de döneminin merkezi yapan faaliyetleri hem Sezgin'in hem de diğer bilim tarihçilerinin araştırmalarında ki örneklerde görmek mümkündür. Öncelikle görülen şey İslam dünyasındaki bilimsel etkinlikler sadece kendi kültür dünyası ile sınırlı değildir. Modern dönemin başlangıcı olan Rönesans üzerinde büyük etkisi vardır. Bu iki dünya arasındaki etkileşimi F. Sezgin şöyle sıralar; 1- 10. yüzyılda Barcelona etrafındaki Pazar yerinde her iki kültür mensuplarının yani Müslümanlarla Hristiyanların temasları vasıtasıyla gerçekleşmiş. 2- Sicilya ve Güney İtalya üzerinden gelen yol. Bu yoldan Arap tıbbı batıya ulaştı. 3- İslam bilimlerinin Bizans üzerinden Avrupa'ya giden yolu (Sezgin,2016: 14-16). Orta Çağ'a bilim tarihçilerinin bakışını ve İslam dünyasının bilim tarihindeki yerini yapılan bilimsel etkinlik örneklerinden ve bilim algısından anlaya biliriz.

Orta Çağ'ın bilim tarihçileri tarafından karanlık dönem olarak algılanması kilisenin baskısı ve dini otoritelerin oluşturduğu skolastisizmin bilimsel gelişmelere ket vurmasından kaynaklanır. Oysa İslam 'da kilise olgusunun yokluğu, iyilik ve lütuf araçlarını ellerinde tutan 
ruhban sınıfının bulunmaması ve dini naslar karşısında onları belirleyen bir ruhani yetkili heyet (concile) in olmayışı felsefe ve bilimi egemen kılmıştır (Corbin,1986: 20). Bu duruma Abbasiler döneminde bilime verilen değer ve dini yetki ile askeri ve siyasi önderliği aynı kişide toplamamış olması da eklenince bilim konuları uzmanların yani ulema denilen kişilerin yetkilerine bırakmıştı (Neill, 2004:314). Bu ise bilimin önünü açmışt1.

Bilimin İslam dünyasında kendine özgü anlam kazanmasına katkı sağlayan unsurlardan biride Arapçanın bilim dili haline gelmesidir. Dil ailesi olarak Sami dil grubuna ait olan Arapça bölgede İslam dininin egemenliği ile ayakta kalan en güçlü dildir. Arapça Kur'an dilidir. Kur'an'daki şekliyle Arabistan yarımadasının bütün yerlileri ve İslam'dan bin yıl önce onunla yan yana olan Bereketli Hilal' de yerleşmiş insanlar tarafından konuşulmuştur (Farukî ve Racî, 1991: 35). İslam öncesi yazılı pek az kayıtları olan bu dil İslam'la birlikte kelime yapılarını sarf, cümle yapılarını da nahiv adı altında geliştirilen gramer çalışmaları ile tamamlamıştır. Sonraki yüzyıllarda Hintçe Farsça ve Grekçeden aldığı kelimelerle zenginleşen Arapça bütün İslam coğrafyasında etkin bir konuma geçerek hem bilim dili hem de Müslümanların ortak ibadet dili olmuştur.

Yunan, Roma ve Hıristiyan kültürlerini kısa sürede tanıyan Müslümanlar bilimin merkezini de yeniden doğuya İslâm dünyasına taşıdılar. Orta çağ Batı' da her ne kadar bilim ve felsefe için karanlık dönem olarak adlandırılsa da İslam dünyasında yüksek düzeyde bir bilim ve felsefe hareketi olarak varlık göstermiştir. Bu durum; "gerek özel olarak İslam uygarlığının ayrılmaz bir parçası olarak, gerekse Batı felsefesinin gelişmesinde önemli bir basamağ oluşturması bakımından evrensel kültür içinde önemli bir yer tutar "(Arslan, 1999: 45).

Abbasiler döneminde Avrupa dışında, Yunan düşüncesinin yayıldığ 1 bütün bölgeler ve İran'dan Hindistan'a kadar birçok toprak imparatorluğa katıldı. Buralardaki kültürel ve bilimsel zemin özellikle tıp, astroloji ve matematik alanları yönetici entelektüellerin dikkatini çekti. Abbasi halifesi el- Me'mun'nun MS. 832'de Beytü'l Hikme (Hikmet Evi)'yi kurması işte bu ortamda gerçekleşti. Onun amacı İslam dünyasında hem felsefenin hem de bilimin gelişmesine katkı yapmaktı (Leaman,1992: 5). Burada doğrudan doğruya Yunanca aslından ve Süryanice çevrilerden Arapçaya kazandırılan eserler felsefe ve bilimin İslam dünyasındaki gelişmesinin de en önemli aracı oldu. El- Me'mun ayrıca Bağdat'ta kütüphane ve bir astronomi gözlemevi kurdu. Fergani ile başlayan gözlemler Sabilerden Battani ve Sabit bin Kurra tarafından devam ettirildi (Mason,2001: 82). Bağdat'ın bilim ve kültür merkezi olmasıyla birlikte bilimsel deyişim ve yeniliklerde İslam dünyasının izleri de görülmeye başlandı. Dönemin dikkat çeken bilim adamları Abbasi hükümdarları tarafindan bu merkeze davet edilerek hem onurlandırıldı hem de kendilerine yeni imkânlar sunuldu. Böylece Batı için yeniden doğuş anlamına gelen Rönesans çağına da etki eden İslam dünyasında matematik, astronomi, fizik, kimya, biyoloji ve tıp alanında yapılan önemli bilimsel çalışmalar ve bilim adamları ortaya çıktı. Bunlardan bazıları şunlardır; IX. Yüzyılda yaşayan Harezmî matematik ve astronomi alanında çalışmıştır. O, Hint Rakamları Üzerine (De Numero Indorum) adını taşıyan eseri ile on rakamlı konumsal Hint rakamlarını tanıtmıştır. Batılılar on tabanlı sistemi bu eserle öğrenmiştir (Topdemir- Unat, 2013: 96). Ayrıca Ömer Hayyam ve Abdulhamit İbn Türk’te önemli matematikçilerdendir.

Me'mun devrinin meşhur astronomi bilgini Latinlerin Alfaganus dediği Fergani ise, “Astronominin Esasları" eseriyle batı dünyasında büyük etki yapmıştır. O, İtalyan şairi Dante üzerinde iz bırakmıştır. IX. ve XI. Yüzyıllar arası büyük yükseliş gösteren İslam astronomisinin önemli bilginleri arasında batıda Albategnius olarak tanınan Battâni, Bîrûni ve İbn Sina’yı da görmekteyiz. Bu dönemde genel olarak astronomi teknolojileri arasında yıldızları gözleme amaciyla oluşturulan rasathaneler ve yön bulmaya yarayan Usturlâp gibi aletleri yer almaktadır (Bayraktar, 1985: 84).

İslam dünyasında doğa bilimleriyle aynı anlamda kullanılan fizik ise iki ekol olarak karşımıza çıkar. Birincisi Aristoteles anlayışına bağlı olan, el- Kindi, İbn Sina ve Farabi tarafindan temsil edilmiş. İkincisi, kelamcılardan Nazzam, Eşşari ve Fahreddin Razi ile bilimcilerden Bîrûni, 
İbn Heysem ve el-Cezeri'de icat ağırlıklı teoriyi yansıtır. Fiziğin bir başka alanı olan Mekanik ve Dinamik konusunda el-Ceziri'nin, Benû Musa kardeşlerin önemli eserleri vardır. Fizik teknolojileri arasında ise, ağırlık ve zaman ölçmeye yarayan aletleri özellikle su ile çalışan saat tekniklerini söyleye biliriz (Bayraktar, 1985:97,107).

İslam'da kimya ve bilimiyle uğraşanların başında Büyük kimyacı Câbir İbn Hayyam gelir. Latinlerin Geber diye tanıdıkları bu düşünürün kimya konusunda yüzlerce eseri vardır. Çoğu Latinceye çevrilmiştir. Câbir'in dışında mutasavvıf Zu'n-Nûn el- Mısrî, Birûni ve bir başka meşhur kimyacı Zekeriyya el- Razi'yi de gösterebiliriz. Kimya teknolojileri arasında ise o dönemde yapılan kimyevi maddelerin elde edilmesini sağlayan ayrıcı ve damıtma firınlarını görebiliyoruz. Ayrıca kimyasal hassas terazilerde yapılmıştır (Bayraktar, 1985: 121,130,134).

İslam dünyasındaki bilimsel başarıların batıya taşınan alanlarından biri de tıp ve hekimliktir. Müslümanlar o dönemde tıp merkezi olarak faaliyet gösteren Cindişapur ve İskenderiye'yi fethetti. Grek medeniyetinin tıp alanındaki iki önemli temsilcisi olan Hipokrat ve Galen ait başta olmak üzere birçok tıp eseri Bağdat'ta aynı zamanda hekimde olan Huneyn ve İbn Kurra tarafından Arapçaya çevrildi. Bununla birlikte halife Mansur zamanında Bağdat'a Cündişapur'dan büyük tıp simaları transfer edildi. Şunu önemle belirtmek gerekir ki Zekeriyya er-Razi ve Avicenna olarak bilinen İbn Sina o devrin tıp sahasında rakipsiz otoriteleri idi. ElKanûn adlı tıp eserinin sahibi olan İbn Sina tıbbın sultanı olarak anılırdı. Ayrıca Batı'da Albucasis olarak tanınan Endülüs'lü ez-Zehravî ameliyat aletlerinin yapımı ve cerrahi alanında dönemine damga vurmuştu (Nasr, 2006:154-174). Bazı örneklerle açıkladığımız İslam dünyasındaki bilimsel faaliyetlerden de anlaşılacağı gibi Batı için karanlık sayılan bir dönemde İslam dünyası altın çağını yaşamıştır. İslam uygarlığının ayrılmaz bir parçası olarak ortaya çıkan bilimsel aktiviteler, Batıda bilim ve felsefesinin gelişmesinde bir basamağı oluşturması bakımından evrensel kültür içinde de önemli yere sahiptir. Bu nedenle de bilim tarihindeki yeri yadsınamaz.

Sonuç olarak değerlendirmemiz şudur; Fuat Sezgin yılı kapsamında yapılanlar sadece toplantı, konferans vb. etkinliklerden ibaret kalırsa ancak günü kurtarır. Oysa asıl dikkat edilmesi gereken, Sezgin'inde birçok söyleşisinde ve özel sohbetlerinde vurguladığ 1 gibi bilim tarihine geçmişte katkı yapan medeniyetin mirasçısı olarak bugünde Müslümanlar bilim dünyasında sadece kendileri için değil tüm insanlığın yararına bir şeyler yapacak bir medeniyet projesi fikrine sahip olup olmadıklarıdır. Maalesef bugün biz de dâhil olmak üzere İslam dünyasının gerek bilime bakışı gerekse bilimsel etkinliklerin motor gücü olan akademik faaliyetleri çokta umut verici değil. Bir medeniyetin bilim tarihin de yer alabilmesi yani bilim tarihinin bir halkası olabilmesi için evrensel ölçekte değer üreten bilim insanlarına sahip olması gerekir.

Başlangıç dönemindeki bilimsel başarıda önemli rol oynayan kültür merkezleri ve bu merkezlere dünyanın değişik yerlerinden gelen bilim adamlanı bilim tarihi içerisinde İslam dünyasına haklı bir ün kazandırmışlardır. Bugün Müslüman kökenli bu nitelikte bilim insanına örnek teşkil edecek ancak bir iki kişiden söz edebiliriz. Pakistanlı fizikçi Abdüsselam ve Aziz Sancar gibi. Ancak bu iki bilim insanı da maalesef Batının yetiştirdiği şahsiyetlerdir. Sadece bunlar değil dünya genelin de itibar gören Aydın Sayılı, Oktay Sinanoğlu, Fuat Sezgin gibi araştırmacı akademisyenlerin durumu da aynı. Müslüman toplulukların sahip olduğu evrensel nitelikte ne bilimsel merkezlerden ne de bilim insanlarından söz edebiliriz. Tam aksine Batı bilim merkezlerinde yetişmiş birkaç Müslüman kökenli bilim insanı olsa da beyin göçü İslam dünyasının en büyük sorunları arasında yer almaktadır. Bu durumun kültürel, sosyal, ekonomik ve siyasal boyutlar başta olmak üzere birçok nedeni vardır.

Müslümanların bugünkü durumu da dikkate alındığında bizi şu sonuçlara götürür. Öncelikle varılan sonuçların doğru algılanabilmesi için olgusal bir hakikat olan bazı gerçeklerin kabullenmesi gerekir. Batı dünyası Rönesans ve Reform hareketiyle birlikte bilim ve felsefe alanında yeniden doğuşu başlatırken, İslam dünyası önce duraklama sonrada gerileme sürecine girmişti. İlk zamanlar sahip oldukları siyasi güç bilim ve düşünce alanındaki olumsuzlukları pek hissettirmemişti. Ancak 18. Yüzyıldan itibaren batı karşısında ortaya çıkan siyasal başarısızlıklar 
19. Yüzyılda da devam etmiş ve 20. Yüzyılın gelindiğinde I. Dünya savaşının sonucuyla da İslam dünyası hem siyasi hem de bilim ve düşünce alanında çöküş yaşamıştı. Bu duruma gelmesinin siyasi nedenleri ayrı bir başlıkta değerlendirilebilir. Ancak bugün Müslümanların bilim ve felsefe adına çağa söyleyecek sözlerinin olmayışı, İslam dünyasında bilimin doğuş koşulları ile karşılaştırıldığında anlaşılacağ 1 kanaatimdeyiz.

Orta çağda Hıristiyanlığın egemen olduğu Batıda Antik Yunan bilim geleneğinin sürdürülemediği dönemde ortaya çıkan İslam dini bulunduğu coğrafyada sağladığı siyasi başarının ardından insanlık için bir medeniyet projesi ortaya koydu. İşte o devrin bilimsel etkinlikleri bu medeniyetin ürünüdür. Maalesef bugün Batı medeniyeti karşısında Müslüman toplulukların herhangi bir teklifi yoktur. Onlar daha çok kendilerini Batı medeniyeti ile bütünleştirecek ideallerin peşindedir. Bunu da bilim ve felsefe alanındaki çabalardan ziyade siyasi bir hedef olarak koymuşlardır. Konulan bu hedeflerde sürdürülebilir özellikten çok uzak ve hamasidir. Örneğin Üniversiteler akademik çalışmaların değerini nitelikten ziyade nicelik üzerinden tanımlaması ve istatistiğin sayılar üzerindeki aldatıcı dilini kullanması gibi. Ayrıca bilimsel gelişmelere hazır altyapısı, kadrosu, geçmişten gelen geleneği, kadrosu, misyon-vizyonu olmayan ve kurumsal sürecini tamamlamayan devlet ve özel sektöre ait birçok üniversitenin kendisini dünyanın en iyi üniversiteler arasında yer alacak hedeflere kilitlemesi yapabileceği hedeflerden onları uzaklaştırmıştır.

Geçmişte İslam dünyasında bilimsel zihniyetin gelişmesine öncülük eden İslam dini algısı da bugün Müslümanların hâkim zihniyetlerinden çok uzaktır. Ayet ve hadislerin emrettiği akletme ve düşünmeyi önceleyen anlayışın yerini, bugün daha çok Kur'an merkezli bakıştan uzak hikâye ağırlıklı, mistik ve mitolojik karakterli, nesnel dünyaya dokunmayı pek düşünmeyen din algısı almıştır. Böyle olunca da çağın idrakine Kur'an'ı sunma şansı ortadan kalkıyor.

Orta çağda Batı'da kilisenin baskısı ve dini otoritelerin oluşturduğu skolastisizm ve ruhban sınıf bilimsel gelişmenin önünde nasıl engel idi ise, Bugünde İslam dünyası, başlangıcında olmamasına rağmen daha sonra mezhep ve cemaatlerin oluşturduğu dini otoritelerin özgür düşünme önündeki engelleriyle karşı karşıyadır. Sadece din algısı değil, seküler bakış açışları da ideolojik saplantılara sahiptir. Bilimi ve moderniteyi kutsayarak onun nesnesi konumuna dönüşmüşlerdir. İster dini ister seküler kaynaklı olsun iktidar hırsının oluşturduğu siyasi çatışma ve kargaşa darbelerin kaynağını oluşturmuştur. Darbeler ise İslam dünyasının en büyük felaketi olmuştur. Her zaman özgün ve özgür düşüncenin önünü kapamıştır. Binlerce insanı mağdur etmiştir. Fuat Sezgin'de 1960 darbesinin mağdurlarından biridir.

İslam dünyasının bilim tarihinin halkalarından biri olmasının başka bir nedeni kendi bilim dilini oluşturmasıdır. Bugün ise, Müslüman topluluklar ortak bilim dili arama düşüncesine dahi sahip değillerdir. Hatta kendi dilleri ile bilim yapılamayacağını savunacak akademik bir yapılanma içindedirler. Yabancı dil hayranlığ 1 bir kısmında sömürü mantığından kalmış anlayışken, bir kısmında da geri kalmışlığın oluşturduğu psikolojinin sonucudur. Dil bilmekle bilim yapmak birbirine karıştırılmıştır.

Sonuç olarak şunu diyebiliriz; Müslümanlar bilim tarihinde evrensel değer üreten bir halka olarak yer alabilmesi için sadece kendileri için değil tüm insanlığın yararına bir şeyler yapmak istiyorlarsa kendilerinin daha önce olduğu gibi bir medeniyet projesi fikrine sahip olmaları gerekir. Sonra geçmişte oluşan altın çağı yeniden yakalamak için Batının Rönesans dönemi ile aynı zamana denk gelen süreçle başlayan büyük kopuş ve çöküşü doğru analiz etmelidirler. Ancak o durumda kopuştan öze dönebilirler ve İslam dünyası evrensel mesajını diğer insanlarla paylaşabilir. İşte Fuat Sezgin'in de batıya anlatmaya çalıştığı o muhteşem geçmişin de bugünkü karşılığı budur. 


\section{Kaynakça}

Arslan, A. (1999). İslam Felsefesi Üzerine, Ankara: Vadi Yayınları.

Bayrakdar, M. (1985). İslam'da Bilim ve Teknoloji Tarihi, Ankara: Türkiye Diyanet Vakfi Yayınlar1.

Corbin, H. (1986). İslam Felsefesi Tarihi, (Çev. H. Hatemi), İstanbul: İletişim Yayınları.

El-Farukî, İ., Râci-L. L. (1991). İslam Kültür Atlası, (Çev. M.O-Z. Kibaroğlu), İstanbul: İnk1lâp Yayınları.

Gribbin, J. (2014). Bilim Tarihi, (Çev. B. Gönülşen), İstanbul: Alfa Basım Yayım.

Leaman, O. (1992). İslam Felsefesine Giriş, (Çev. T. Koç), Kayseri: Rey Yayıncılık.

Mason, S. F. (2001). Bilimler Tarihi, (Çev. U. Daybelge), Ankara: Kültür Bakanlı̆̆ı.

McNeill, W. H. (2004). Dünya Tarihi, (Çev. A. Şenel), Ankara: İmge Kitabevi Yayınları.

Nasr, S. H. (2006). İslam ve Bilim, (Çev. İ. Kutluer), İstanbul: İnsan Yayınları.

Ronan, C.A. (2003). Bilim Tarihi, (Çev.E. İhsanoğlu-F. Günergün), Ankara: Tübitak Yayınları

Sezgin, F. (2008). İslam'da Bilim ve Teknik Cilt I, (Çev: Abdurrahman Aliy), İstanbul: İstanbul Büyükşehir Belediyesi Kültür A.Ş. Yayınları.

Sezgin, F. (2016). Amerika'nın Keşfinde Müslümanlar, Söyleşi ve Konferans, Ağustos 2016, Kayseri, Editör, Prof. Dr. Kadir Temuçin s.19)

Topdemir, H. G. ve Unat, Y. (2013). Bilim Tarihi, Ankara: Pegem Akademi Yayınları. 